\title{
Production of nepheline/quartz ceramics from geopolymer mortars
}

\author{
C. Kuenzel ${ }^{1,2}$, L.M Grover ${ }^{4}$, L. Vandeperre ${ }^{2}$, A. R. Boccaccini ${ }^{2,3}$, C. R. Cheeseman ${ }^{1} *$
}

${ }^{1}$ Department of Civil and Environmental Engineering, Imperial College London, South Kensington Campus, London SW7 2AZ, United Kingdom

${ }^{2}$ Centre for Advanced Structural Ceramics, Department of Materials, Imperial College London, South Kensington Campus, London SW7 2AZ, United Kingdom

${ }^{3}$ Institute of Biomaterials, University of Erlangen-Nuremberg, Cauerstrasse 6, 91058 Erlangen, Germany

${ }^{4}$ School of Chemical Engineering, University of Birmingham Edgbaston, Birmingham B15 2TT, United Kingdom

* Corresponding author: c.cheeseman@imperial.ac.uk

Tel: 0044 (0)20 75945971

\begin{abstract}
This research has investigated the mechanical properties and microstructure of metakaolin derived geopolymer mortars containing $50 \%$ by weight of silica sand, after exposure to temperatures up to $1200{ }^{\circ} \mathrm{C}$. The compressive strength, porosity and microstructure of the geopolymer mortar samples were not significantly affected by temperatures up to $800{ }^{\circ} \mathrm{C}$. Nepheline $\left(\mathrm{NaAlSiO}_{4}\right)$ and carnegieite $\left(\mathrm{NaAlSiO}_{4}\right)$ form at $900{ }^{\circ} \mathrm{C}$ in the geopolymer phase and after exposure to $1000{ }^{\circ} \mathrm{C}$ the mortar samples were transformed into polycrystalline nepheline/quartz ceramics with relatively high compressive strength $(\sim 275 \mathrm{MPa})$ and high Vickers hardness ( 350 HV). Between 1000 and $1200{ }^{\circ} \mathrm{C}$ the samples soften with gas evolution causing the formation of closed porosity that reduced sample density and limited the mechanical properties.
\end{abstract}


Keywords: ceramics; geopolymers; sintering; mechanical properties; microstructure

\section{INTRODUCTION}

Geopolymers contain silicate and aluminate groups linked to form an amorphous network [1]. Oxygen tetrahedra containing $\mathrm{Al}^{3+}$ ions have a negative charge which is neutralised by an alkali metal ion [2]. The polymerisation reaction can use alumino-silicate minerals such as metakaolin and an alkali activating solution such as $\mathrm{NaOH}$ as the primary raw materials [3]. Geopolymer synthesis involves dissolution and condensation polymerisation [4-6]. The condensation reaction occurs at room temperature and therefore geopolymers are often regarded as cementitious materials. However, at high temperatures crystalline phases are formed and sintering reactions result in the formation of ceramic products.

Geopolymers have improved acid and fire resistance compared to most cementitious matrixes, and unlike concrete containing Portland cement, the maximum strength is achieved significantly before 28 days [4, 7-10]. Several potential applications have been proposed for geopolymer concrete including use in fire resistant panels, insulation materials and geopolymer concrete precast construction products [11-14]. A novel potential application for geopolymers is as a precursor for the production of ceramics. Geopolymer mortar slurries can be cast into the designated near shape and allowed to cure prior to sintering, with the formation of crystalline phases and improved properties. This route to ceramic production has advantages associated with high green (unfired) strength and increased dimensional stability during the sintering process when compared to conventional ceramic production involving powder pressing and sintering. 
Previous work on the effect of high temperatures on geopolymers has examined phase changes using XRD and NMR [15-20]. Different charge balancing cations (Na, K and Cs) were investigated and the molar Al:Si ratio was varied. It was shown that during heating the amorphous geopolymer transforms into crystalline phases [19-21], with pure geopolymers showing excessive shrinkage when sintered between 850 and $1000{ }^{\circ} \mathrm{C}[14,18]$. This shrinkage may be controlled by adding inert filler to the geopolymer to form a geopolymer mortar. Furthermore, the presence of discrete filler particles in a geopolymer matrix may increase the strength and fracture toughness of the ceramic subsequently formed by heat treatment $[22,23]$.

The objective of this work was to investigate the effect of temperature on the properties and microstructure of $\mathrm{Na}$ based metakaolin derived geopolymer mortars containing $50 \%$ by weight of silica sand. Geopolymer mortar samples have been prepared using silica sand with different particle size distributions and the properties and microstructure of the mortars after exposure to temperatures up to $1200{ }^{\circ} \mathrm{C}$ are reported.

\section{EXPERIMENTAL}

\subsection{Materials}

Geopolymers were prepared using metakaolin (MK, Metastar 501, Imerys, UK), sodium silicate solution (VWR International, Philadelphia, USA), sodium hydroxide ( $\mathrm{NaOH}$, Fischer, Pittsburgh, USA) and distilled water. The metakaolin had a median particle size of $3.9 \mu \mathrm{m}$ and chemical composition determined by XRF (wt\%) of $56.0 \mathrm{SiO}_{2}, 38.1 \mathrm{Al}_{2} \mathrm{O}_{3}$ and 5.9 other oxides. 


\subsection{Preparation of geopolymer mortar samples}

The Al:Si:Na: $\mathrm{H}_{2} \mathrm{O}$ molar ratio of the geopolymer binder was 1:2:1:8. Previous research comparing different $\mathrm{Al}$ :Si ratios has shown that a ratio of 2 results in relatively high strength geopolymers [24-27]. The water content of 8 moles per mole of Al gave adequate paste workability and good geopolymer strength development [28-30].

The geopolymer mortar samples contained $50 \mathrm{wt} \%$ of silica sand (Redhill 110, Sibelco, UK). The as-received sand was laboratory disc milled (TEMA Machinery Ltd) to give samples with three different particle size distributions (coarse, medium and fine) as shown in Figure 1. The corresponding geopolymer mortar samples are labelled GP-coarse, GP-medium and GPfine. Control samples without sand addition were also prepared (pure GP).

The activating solution was formed by mixing sodium silicate solution, water and $\mathrm{NaOH}$ for 24 hours. This was then added to metakaolin and sand to give a 50:50 geopolymer: sand ratio. The paste was mixed for 3 minutes using a planetary mixer (ELE International Ltd.) and the homogenous paste formed cast into $8 \times 8 \times 40 \mathrm{~mm}^{3}$ plastic moulds (acryl nitril-butadienstyrol-copolymer (ABS)). These were vibrated for 15 minutes to remove air bubbles. Samples were then cured for 77 days at $22 \pm 3{ }^{\circ} \mathrm{C}$, initially in the mould and then in sealed polyethylene bags.

\subsection{Thermal treatment}

The as-cured mortar samples had a high water content of approximately $16.9 \mathrm{wt} \%$. The mortar samples were therefore dried at $35{ }^{\circ} \mathrm{C}$ for 24 hours prior to thermal treatment. This initial drying resulted in a loss of approximately $12.5 \mathrm{wt} \%$ of the total water and was 
necessary to avoid excessive shrinkage cracking during subsequent heat treatment. Samples were then heated at $20{ }^{\circ} \mathrm{C} /$ minute to the treatment temperature, held at temperature for 2 hours and then allowed to cool with the furnace (Carbolite, UK).

Changes in geopolymer mortar sample mass as a function of temperature were determined using combined thermogravimetric analysis and differential scanning calorimetry (TGA/DSC, Netzsch-STA 449 f1 Jupiter, Germany).

Shrinkage as a function of temperature was determined using dilatometry (Netzsch 402 E, Germany) on $8 \mathrm{~mm}$ cube samples that were heated to a final temperature of $1000{ }^{\circ} \mathrm{C}$ at 10 ${ }^{\circ} \mathrm{C} /$ minute in a He atmosphere.

The total porosity and open porosity of heat treated geopolymer mortar samples was determined using Archimedes' principle [31], with the theoretical density determined on milled samples using pycnometry (AccuPyc II 1340 He pycnometer, Micromeritics, Georgia, USA).

\subsection{Physical property characterisation}

Vickers hardness was determined on polished samples (Zwick/Roell Indentec ZHV, Germany) by applying a $1000 \mathrm{~g}$ load for 10 seconds. The data reported represents the average of nine samples. Flexural strength was measured using three point bending testing on samples with dimensions of $8 \times 8 \times 50 \mathrm{~mm}^{3}$. The distance of the support spam was $30 \mathrm{~mm}$ and the loading rate was $0.2 \mathrm{~mm} /$ minute (Zwick/Roell Z2.5, Germany). The compressive strength was determined on $8 \mathrm{~mm}$ cube samples using a loading rate of $0.2 \mathrm{~mm} /$ minute (Zwick/Roell 
Z010, Germany). For both strength measurements the data reported is the average from five test samples.

\subsection{Micro-structural characterisation}

Crystalline phases were analysed by x-ray diffraction (XRD, PAN analytical X-Pert Pro MPD, Philips, Netherlands). The $50 \mathrm{wt} \%$ sand present in the geopolymer mortar samples dominated the XRD data and therefore the geopolymer samples without sand addition (pure GP) were analysed.

The effect of treatment temperature on the microstructure of mortar samples was investigated using scanning electron microscopy (SEM) of gold coated polished surfaces (JEOL-5610LV, Japan).

\section{RESULTS}

The physical properties (density, porosity, strength and Vickers hardness) of 75 day cured geopolymers and mortars are given in Table 1. The addition of filler influences the compressive strength of geopolymer samples and is increased using finer fillers. The flexural strength and porosity were not significantly affected by the filler size.

TGA/DSC data for metakaolin geopolymer (pure GP) is shown in Figure 2. The sample mass rapidly decreases between room temperature and $200{ }^{\circ} \mathrm{C}$ due to water loss, but then remains relatively constant up to temperatures in excess of $1200^{\circ} \mathrm{C}$. DSC data indicates a minor peak at just over $850{ }^{\circ} \mathrm{C}$ due to the transformation of the amorphous geopolymer to crystalline phases. 
Dilatometry data showing the length change in geopolymer mortar samples during heating to $1000{ }^{\circ} \mathrm{C}$ is shown in Figure 3. All samples shrink at $\sim 200{ }^{\circ} \mathrm{C}$ due to water loss, expand at around $570{ }^{\circ} \mathrm{C}$ due to the $\alpha$ to $\beta$ quartz phase change in the filler particles, and show large shrinkage associated with sintering above $750{ }^{\circ} \mathrm{C}$. The size of the sand particles did not affect initial shrinkage or expansion, but does influence the magnitude of the sintering shrinkage above $750{ }^{\circ} \mathrm{C}$, with geopolymer mortars containing fine sand showing increased shrinkage compared to samples containing coarse sand.

Figure 4 shows the effect of treatment temperature on the compressive strength of geopolymer mortars. Pure geopolymers could not be measured due to extensive shrinkage during heating at $110{ }^{\circ} \mathrm{C}$. Previous research had shown that metakaolin based geopolymers contain structural water [32]. When this water is removed geopolymers shrink and crack [32]. However, this shrinkage can be significantly reduced when filler particles are present and during drying the compressive strength increases between $7 \%$ (GP-coarse) and $20 \%$ (GPfine). For temperatures up to $800{ }^{\circ} \mathrm{C}$ the compressive strength remains relative constant but then increases significantly for samples containing medium and fine sand as sintering occurs. Maximum compressive strengths of $\sim 275 \mathrm{MPa}$ were obtained for geopolymer mortars containing fine sand (GP-fine), with GP-medium and GP-coarse mortar samples having lower strengths. The compressive strength decreases for samples at $1100{ }^{\circ} \mathrm{C}$ and exposure to 1200 ${ }^{\circ} \mathrm{C}$ caused samples to melt and deform so that accurate compressive strength data could not be determined.

Flexural strength data is shown in Figure 5, with geopolymer mortars containing fine filler having the highest strengths. However, in contrast to the compressive strength data, the 
flexural strength decreases after exposure to temperatures up to $750^{\circ} \mathrm{C}$, stabilises and then increases between 900 and $1000{ }^{\circ} \mathrm{C}$.

Figure 6 shows the effect of exposure temperature on Vickers hardness of geopolymer mortar samples. Vickers hardness increases to a maximum at $\sim 1000{ }^{\circ} \mathrm{C}$ and this is associated with the reduction in porosity and the changes in the crystalline phases present. Further increases in temperature cause a reduction in hardness which is influenced by the sand particle size, with fine sand resulting in higher hardness compared to medium or coarse sand.

The change in total and open porosity and density of the geopolymer mortar samples after exposure to temperatures up to $1200{ }^{\circ} \mathrm{C}$ is shown in Figure 7. Data is presented for the GPmedium samples as other samples gave similar results. The total porosity remains relatively constant at approximately 35 volume $\%$ up to $\sim 800{ }^{\circ} \mathrm{C}$. At higher temperatures there is a rapid reduction in both total and open porosity associated with sintering. Over the whole temperature range the density of geopolymer mortars remained constant at around $2.7 \mathrm{~g} / \mathrm{m}^{3}$. Changes in the density of the geopolymer phase are difficult to detect due to the high concentration of sand in the samples.

The changes in crystalline phases present in the pure metakaolin geopolymer (pure GP) determined by XRD are given in Figure 8 and confirm the results found by other researcher [21]. Below $850^{\circ} \mathrm{C}$ a broad peak characteristic of amorphous material with some crystalline silica (quartz) present in the metakaolin is observed. After exposure to $900{ }^{\circ} \mathrm{C}$, nepheline $\left(\mathrm{NaAlSiO}_{4}\right)$ with traces of carnegieite $\left(\mathrm{NaAlSiO}_{4}\right)$ form. After heating to $1000{ }^{\circ} \mathrm{C}$ the geopolymer is transformed into a crystalline material consisting predominantly of nepheline and on heating to $1100{ }^{\circ} \mathrm{C}$ amorphous phases reform, giving high background data at $2 \theta \sim 10^{\circ}$ 
and $\sim 25^{\circ}$. Nepheline $\left(\mathrm{NaAlSiO}_{4}\right)$ is also present together with some carnegieite $\left(\mathrm{NaAlSiO}_{4}\right)$. These crystalline phases were also present in samples treated at $1200{ }^{\circ} \mathrm{C}$.

The microstructures of GP-medium after exposure to temperatures of $850{ }^{\circ} \mathrm{C}, 900{ }^{\circ} \mathrm{C}$ and $1200{ }^{\circ} \mathrm{C}$ are shown in Figure 9. These are representative of the other geopolymer mortar samples prepared in this work. Between $100{ }^{\circ} \mathrm{C}$ and $850{ }^{\circ} \mathrm{C}$ no significant changes in the microstructure of the geopolymer mortar samples were observed and the sand particles are clearly evident. After treating at $900{ }^{\circ} \mathrm{C}$ small pores form throughout the sample as the material transforms from an amorphous geopolymer into a nepheline crystalline ceramic and the sand particles are no longer visible. Heating the geopolymer mortar samples to $1200{ }^{\circ} \mathrm{C}$ resulted in the formation of large spherical pores with diameters up to $200 \mu \mathrm{m}$.

\section{DISCUSSION}

The effect of temperature on the mechanical properties and microstructure of geopolymer mortar samples has been investigated. This has shown that the hardness and compressive strength depend on the filler particle size and exposure temperature. By using fine filler the mechanical properties can be significantly improved, although this increases initial paste viscosity and reduces mix workability.

The exotherm at $\sim 700{ }^{\circ} \mathrm{C}$ in the DSC data indicates that sintering of the geopolymer occurs. Furthermore, dilatometry results show that using filler reduced the initial shrinkage associated with the loss of free water from $8 \%$ to $\sim 1.5 \%$ independent of the filler size. Adding sand results in an expansion at $570{ }^{\circ} \mathrm{C}$ due to the phase transition of $\alpha$ - to $\beta$-quartz, as shown in Figure $10[33,34]$. Above $~ 800{ }^{\circ} \mathrm{C}$ geopolymer samples start to sinter and the pure geopolymers shrinks by up to $30 \%$. However, by adding filler the total shrinkage can be 
reduced to $\sim 6 \%$. Geopolymer mortars containing fine filler show slightly higher shrinkage, indicating that these samples form a more dense material.

Exposure to temperatures up to $800{ }^{\circ} \mathrm{C}$ does not significantly change the open and total porosity. However, between 800 and $1200{ }^{\circ} \mathrm{C}$ the open and total porosity decrease due to sintering and sample densification. Although the open porosity decreases with increasing temperature, the total porosity remains constant at temperatures above $1000{ }^{\circ} \mathrm{C}$ due to the creation of closed porosity formed by partial melting of the geopolymer matrix and gas evolution, as shown in the SEM pictures. The DSC data show that geopolymers melt at $\sim 1100{ }^{\circ} \mathrm{C}$, which is in agreement with the phase diagram for geopolymers, shown in Figure 10.

Heat treatment has a significant impact on the mechanical properties of geopolymer mortars. It has been shown that a direct heating of "wet" as cured geopolymer samples should be avoided. During heating of geopolymer samples water evaporates. However, because the water is contained in micro-porosity the rate of evaporation is low [35]. This means that with increasing temperature pressure increases in the geopolymer sample due to expanding water vapour. This pressure causes cracking and the flexural strength decreases. By controlling the drying temperature, most of the water can be removed slowly and the formation of cracks reduced.

Subsequent heating to $800{ }^{\circ} \mathrm{C}$ does not have a significant effect on compressive strength and Vickers hardness but causes a reduction in flexural strength. The reduction in flexural strength is probably associated with phase transition of the sand filler to give $\beta$ quartz. It is most likely that during that process micro-cracks are formed within the interfacial transition 
zone (ITZ) around filler particles where the microstructure is altered [36]. While these cracks do not significantly affect compressive strength the flexural strength is reduced. At temperatures above $850{ }^{\circ} \mathrm{C}$ sintering occurs and this decreases porosity and causes the Vickers hardness, compressive and flexural strengths to increase. The results show that the highest mechanical strengths and hardness are obtained for geopolymers containing fine filler particles. Heating above $1000{ }^{\circ} \mathrm{C}$ causes the hardness and compressive strength to decrease due to the formation of a partially amorphous phase in the matrix with lower mechanical strength, as shown in Figure 8.

The influence of the filler size is more important for compressive strength compared to flexural strength. This effect has been explained for concrete as with increasing filler size, the average crack width in the cement phase increases [37]. A similar effect occurs in geopolymer systems. With decreasing filler size, the crack width in the geopolymer phase decreases and during sintering these cracks tend to heal. However, when the filler particle size increases above $100 \mu \mathrm{m}$, the cracks are too large to heal. This explanation is supported by the flexural strength data which shows an increase of flexural strength with sintering.

At temperatures above $1000{ }^{\circ} \mathrm{C}$ the compressive strength decreases and heating above 1100 ${ }^{\circ} \mathrm{C}$ causes sample distortion. This is associated with the re-appearance of an amorphous phase in the material. Distortion of the samples did not allow measurement of compressive strength, while hardness was reduced. These changes in properties correlate with an increase in porosity and the formation of large pores in the microstructure, as shown in Figure 9. 


\section{CONCLUSIONS}

The mechanical properties and microstructure of metakaolin based geopolymer mortar samples after exposure to high temperatures have been investigated. The addition of fine silica sand filler particles enhances the mechanical properties of both the as-formed geopolymers and samples heat treated at temperatures up to $1000{ }^{\circ} \mathrm{C}$. The hardness, compressive strength and geopolymer microstructure remain relatively constant after heating to temperatures up to $800{ }^{\circ} \mathrm{C}$, whereas the flexural strength decreases due to the formation of micro-cracks at the ITZ. Above $800{ }^{\circ} \mathrm{C}$ a sodium aluminate crystalline phase forms and the geopolymer phase transforms to nepheline and carnegieite on heating to $900{ }^{\circ} \mathrm{C}$. These crystalline phases soften and partially melt at temperatures above $1000{ }^{\circ} \mathrm{C}$ and coarse closed pores are formed in the microstructure that significantly reduces the mechanical properties. Heating metakaolin geopolymer mortar samples containing fine quartz filler particles to 1000 ${ }^{\circ} \mathrm{C}$ represents a novel way to prepare polycrystalline nepheline/quartz ceramics.

\section{ACKNOWLEDGEMENTS}

The authors would like to thank the Decommissioning, Immobilization and Management of Nuclear waste for Disposal (DIAMOND) consortium and the EPSRC for the funding of this project.

\section{REFERENCES}

1. Davidovits, J., Geopolymers and geopolymeric materials. Journal of Thermal Analysis, 1989. 35: p. $429-441$.

2. Hewayde, E., et al., Effect of geopolymer cement on microstructure, compressive strength and sulphuric acid resistance of concrete. Magazine of Concrete Research, 2006. 58(5): p. 321-331.

3. Swanepoel, J.C. and C.A. Strydom, Utilisation of fly ash in a geopolymeric material. Applied Geochemistry, 2002. 17(8): p. 1143-1148. 
4. Davidovits, J., Geopolymers: Inorganic Polymeric New Materials. Journal of Thermal Analysis, 1991. 37(8): p. 1633-1656.

5. Hos, J.P., P.G. Mccormick, and L.T. Byrne, Investigation of a synthetic aluminosilicate inorganic polymer. Journal of Materials Science, 2002. 37: p. 2311-2316.

6. $\quad$ Provis, J.L., et al., The role of mathematical modelling and gel chemistry in advancing geopolymer technology Chemical Engineering Research and Design, 2005. 83(A7): p. 853-860.

7. Komnitsas, K. and D. Zaharaki, Geopolymerisation: A review and prospects for the minerals industry. Minerals Engineering, 2007. 20(14): p. 1261-1277.

8. Palomo, A., et al., Chemical stability of cementitious materials based on metakaolin. Cement and Concrete Research, 1999. 29: p. 997-1004.

9. Palomo, A. and J.I. Lopez de la Fuente, Alkali-activated cementitous materials: Alternative matrices for the immobilisation of hazardous wastes Part I. Stabilisation of boron. Cement and Concrete Research, 2003. 33: p. 281-288.

10. Silva, P.D., K. Sagoe-Crenstil, and V. Sirivivatnanon, Kinetics of geopolymerization: Role of Al2O3 and SiO2. Cement and Concrete Research, 2007. 37(4): p. 512-518.

11. Davidovits, J., Geopolymer Chemistry and Applications. 2008, Saint-Quentin, France: Institut Geopolymere.

12. Singh, M., et al., Global Roadmap for Ceramic and Glass Technology, ed. S. Freiman. 2007, New York, USA: John Wiley \& Sons.

13. Nair, B.G., Q. Zhao, and R.F. Cooper, Geopolymer matrices with improved hydrothermal corrosion resistance for high-temperature applications. Journal of Materials Science, 2007. 42: p. 3083-3091.

14. Kamseu, E., et al., Enhanced thermal stability in K2O-metakaolin-based geopolymer concretes by Al2O3 and SiO2 fillers addition. Journal of Materials Science, 2010. 45(7): p. 1715-1724.

15. Valeria, F.F., et al., Synthisis and thermal behaviour of potassium sialate geopolymers. Materials Letters, 2003. 57: p. 1477-1482.

16. Bell, J.L., P.E. Driemeyer, and W.M. Kriven, Formation of Ceramics from Metakaolin-Based Geopolymers. Part II: K-Based Geopolymer. Journal of the American Ceramic Society, 2009. 92(3): p. 607-615. 
17. Bell, J.L., P.E. Driemeyer, and W.M. Kriven, Formation of Ceramics from Metakaolin-Based Geopolymers: Part I: Cs-Based Geopolymer. Journal of the American Ceramic Society, 2009. 92(1): p. $1-8$.

18. Duxson, P., G.C. Lukey, and J.S.J. van Deventer, Physical evolution of Na-geopolymer derived from metakaolin up to $1000{ }^{\circ} \mathrm{C}$. Journal of Materials Science, 2007. 42(9): p. 3044-3054.

19. Duxson, P., G.C. Lukey, and J.S.J. van Deventer, Thermal evolution of metakaolin geopolymers: Part 1 - Physical evolution. Journal of Non-Crystalline Solids, 2006. 352(52-54): p. 5541-5555.

20. Duxson, P., G.C. Lukey, and J.S.J. van Deventer, The thermal evolution of metakaolin geopolymers: Part 2 - Phase stability and structural development. Journal of Non-Crystalline Solids, 2007. 353(2223): p. 2186-2200.

21. Buchwald, A., et al., Geopolymeric binders with different fine fillers-Phase transformations at high temperatures. Applied Clay Science, 2009. 46: p. 190-195.

22. Donald, I.W. and P.W. McMillan, Review Ceramic-matrix composites. Journal of Materials Science, 1976. 11(5): p. 949-972.

23. Brennan, J.J. and K.M. Prewo, Silicon carbide fibre reinforced glass-ceramic matrix composites exhibiting high strength and toughness. Journal of Materials Science, 1982. 17(8): p. 2371-2383.

24. Rowles, M. and B. O'Conner, Chemical optimisation of the compressive strength of aluminosilicate geopolymers synthesised by sodium silicate activation of metakaolinite. Journal of Materials Chemistry, 2003. 13: p. 1161-1165.

25. Stevenson, M. and K. Sagoe-Crentsil, Relationships between composition, structure and strength of inorganic polymers : Part I Metakaolin-derived inorganic polymers. Journal of Materials Science, 2005. 40(8): p. 2023-2036.

26. Latella, B.A., et al., Mechanical properties of metakaolin-based geopolymers with molar ratios of Si/Al 2 and Na/Al 1. Journal of Materials Science, 2008. 43(8): p. 2693-2699.

27. Perera, D.S., et al., Influence of curing schedule on the integrity of geopolymers. Journal of Materials Science, 2007. 42(9): p. 3099-3106.

28. Kuenzel, C., Nuclear waste encapsulation using metakaolin based geopolymers, in Department of Civil and Environmental Engineering. 2012, Imperial College London: London.

29. De Silva, P., K. Sagoe-Crenstil, and V. Sirivivatnanon, Kinetics of geopolymerization: Role of Al2O3 and SiO2. Cement and Concrete Research, 2007. 37(4): p. 512-518. 
30. Perera, D.S., et al., Fe speciation in geopolymers with Si/Al molar ratio of $\sim 2$. Journal of the European Ceramic Society, 2007. 27(7): p. 2697-2703.

31. Standards, B., BS EN ISO 10545-3 Ceramic tiles-Part 3: Determination of water absorption, apparent porosity, apparent relative density and bulk density. 1997.

32. Kuenzel, C., et al., An assessment of drying shrinkage in metakaolin-based geopolymers. Journal of the American Ceramic Society (accepted), 2012.

33. Lakshtanov, D.L., S.V. Sinogeikin, and J.D. Bass, High-temperature phase transition and elasticity of silica polymorphs. Physics and Chemistry of Minerals, 2007. 34: p. 11-22.

34. Subaer and A. van Riessen, Thermo-mechanical and microstructural characterisation of sodiumpoly(sialate-siloxo) (Na-PSS) geopolymers. Journal of Materials Science, 2007. 42: p. 3117-3123.

35. Kong, D.L.Y., J.G. Sanjayan, and K. Sagoe-Crentsil, Comparative performance of geopolymers made with metakaolin and fly ash after exposure to elevated temperatures. Cement and Concrete Research, 2007. 37(12): p. 1583-1589.

36. Scrivener, K.L., A.K. Crumbie, and P. Laugesen, The Interfacial Transition Zone (ITZ) Between Cement Paste and Aggregate in Concrete. Interface Science, 2004. 12(4): p. 411-421.

37. Grassl, P., H.S. Wong, and N.R. Buenfeld, Influence of aggregate size and volume fraction on shrinkage induced micro-cracking of concrete and mortar. Cement and Concrete Research, 2010. 40(1): p. 85-93.

38. Bale, C.W., et al., FactSage Thermochemical Software and Databases. 2012. 


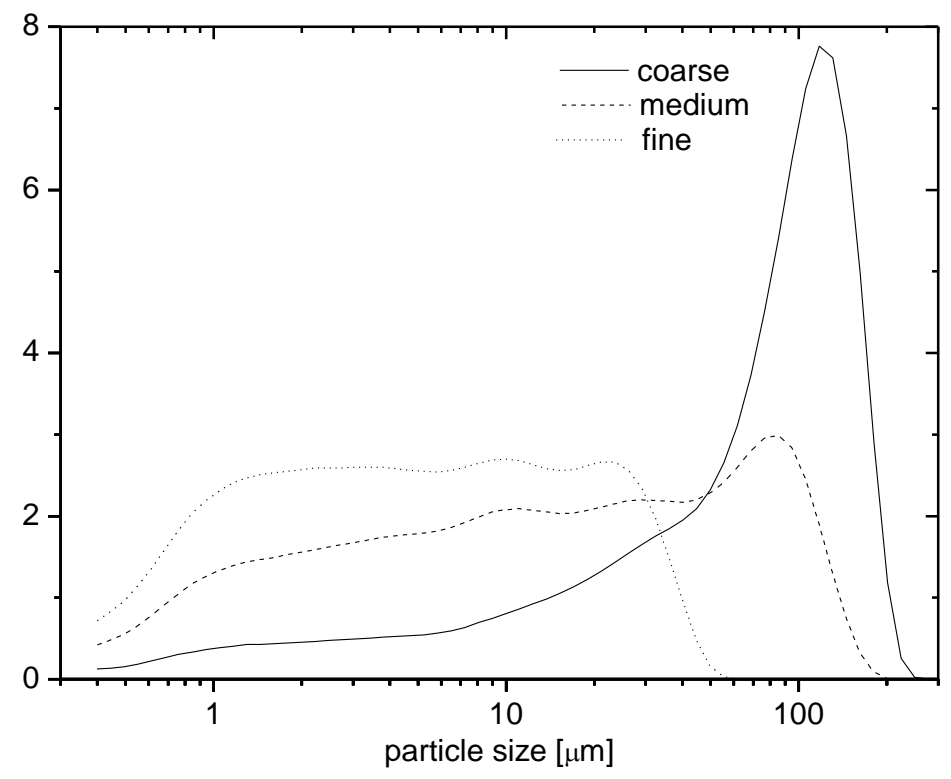

Figure 1: Particle size distribution of the different grades of sand used to form geopolymer mortar samples. 


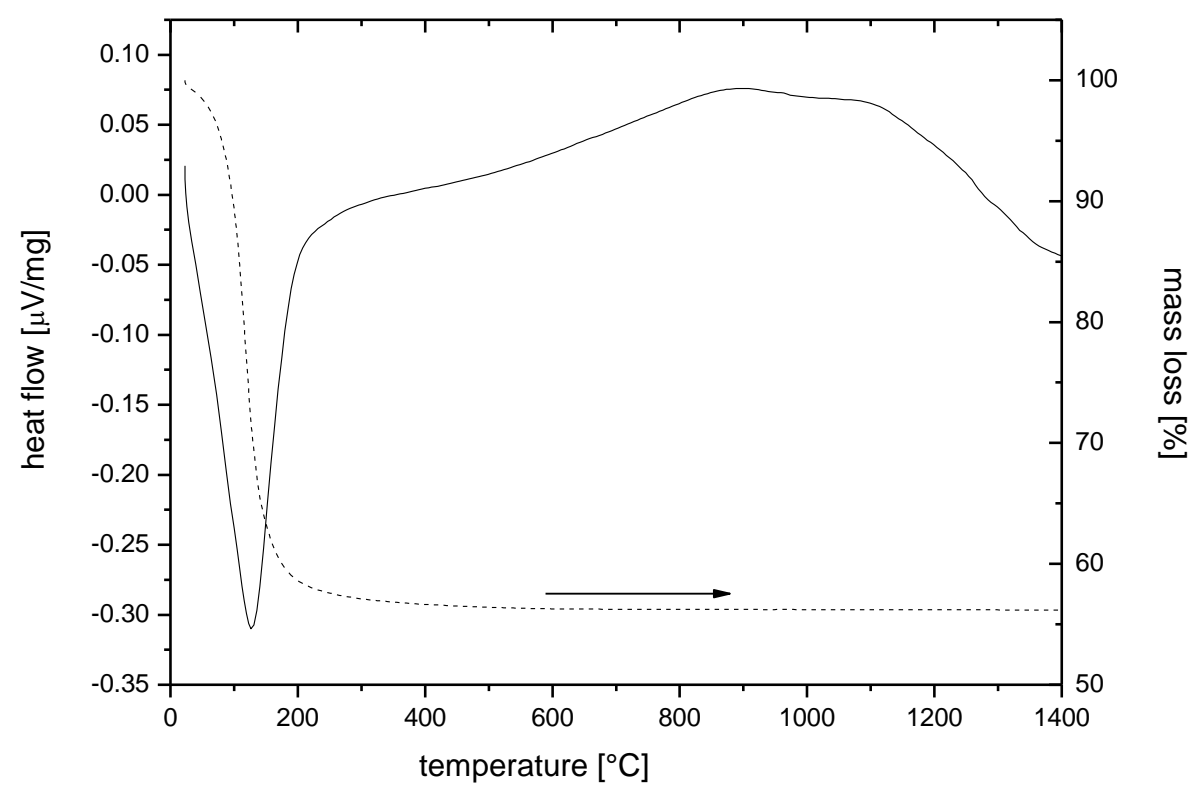

Figure 2: TGA/DSC data for 75 day cured metakaolin geopolymer (GP-pure) with Al:Si: $\mathrm{Na}_{2} \mathrm{H}_{2} \mathrm{O}$ molar ratio of 1:2:1:8.

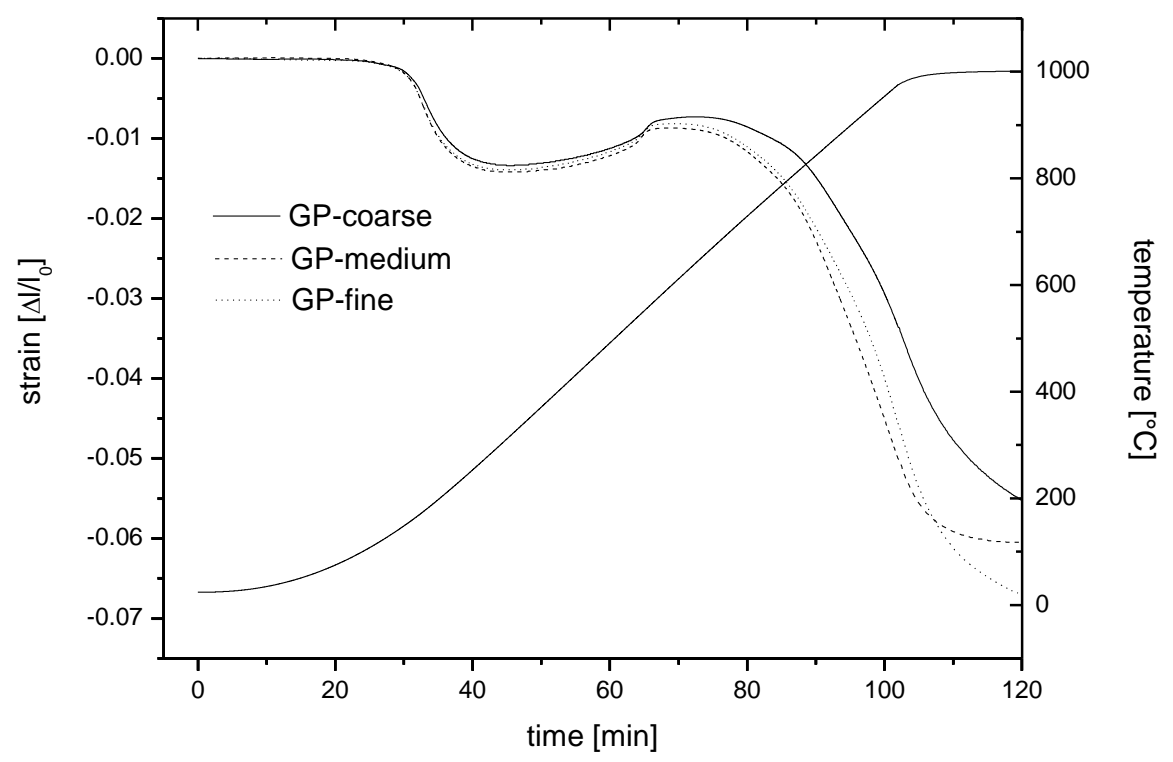


Figure 3: Dilatometer results the geopolymer mortar samples GP-coarse, GP-medium and GP-fine.

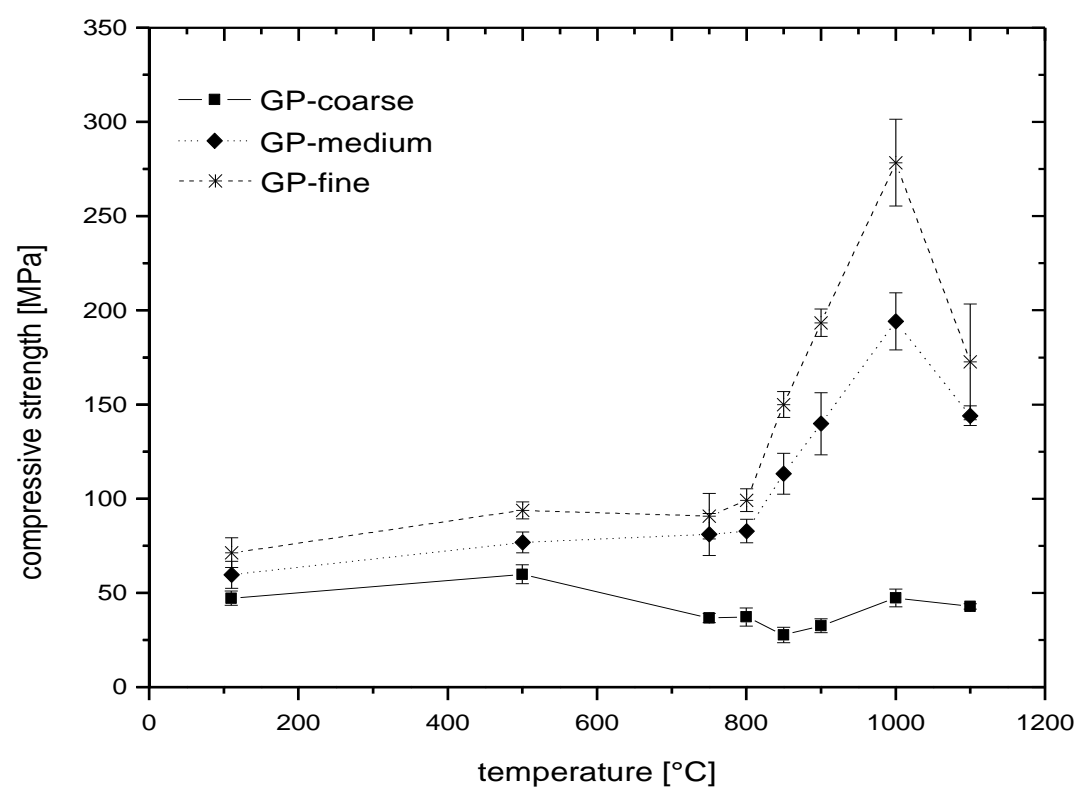

Figure 4: Compressive strength of geopolymer/sand mortar samples as a function of the heat treatment temperature. Data shown are the average and standard deviation of 5 measurements. 


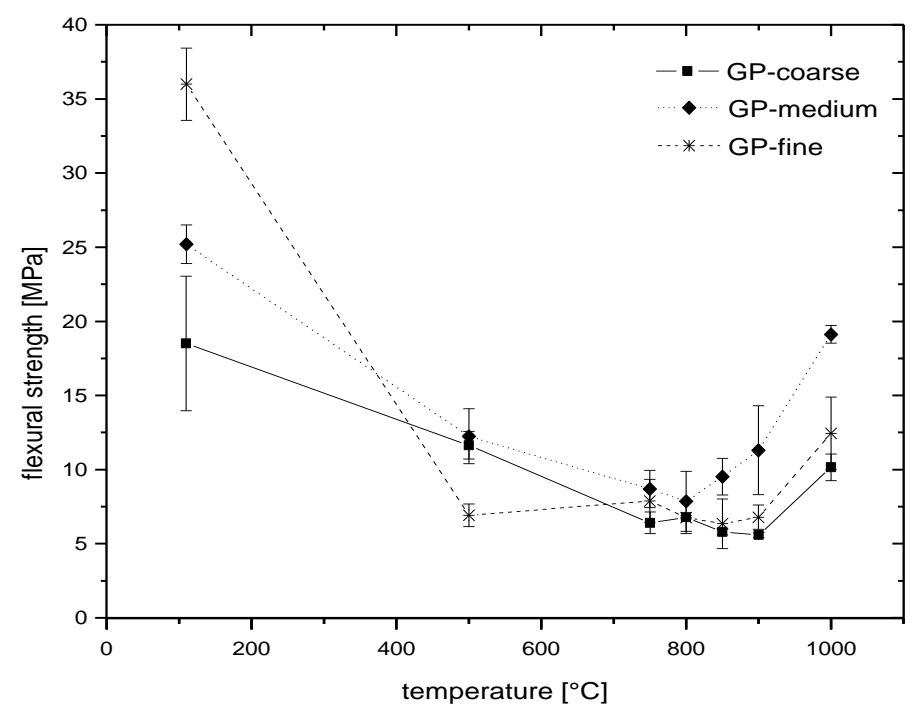

Figure 5: Flexural strength of geopolymer/sand mortar samples as a function of the heat treatment temperature. Data shown are the average and standard deviation of 5 measurements.

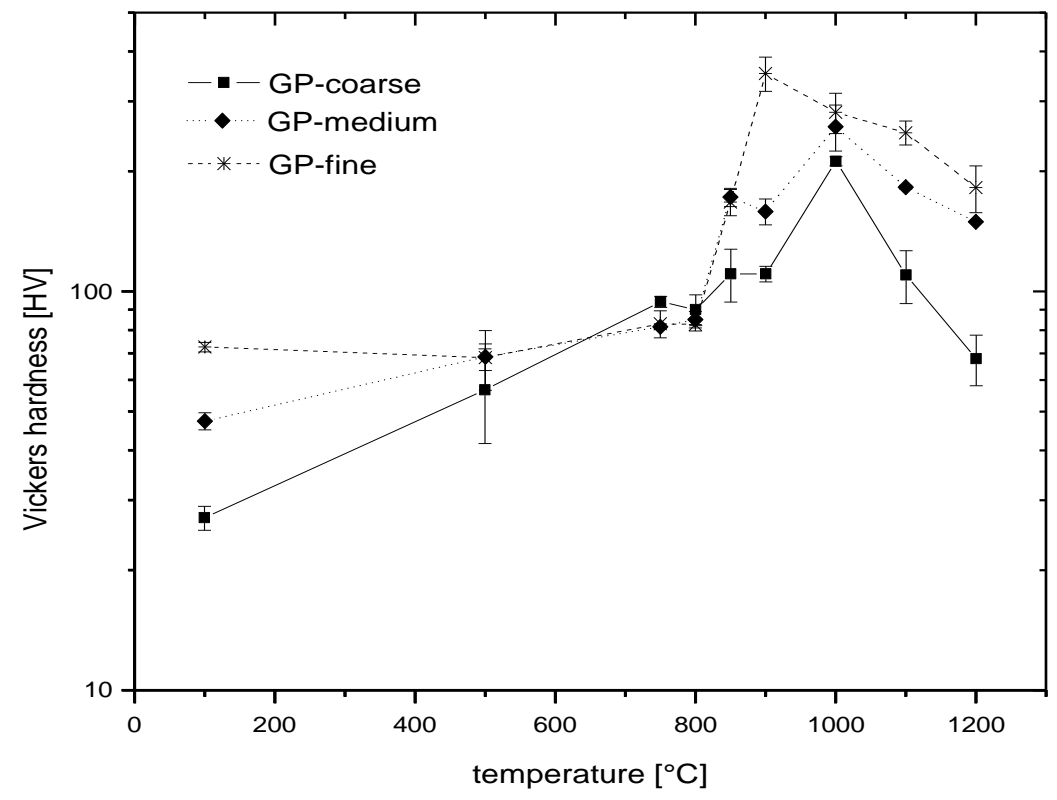


Figure 6: Change of hardness versus temperature for geopolymer samples (pure GP) containing no sand. Data points are averages of 9 measurements.

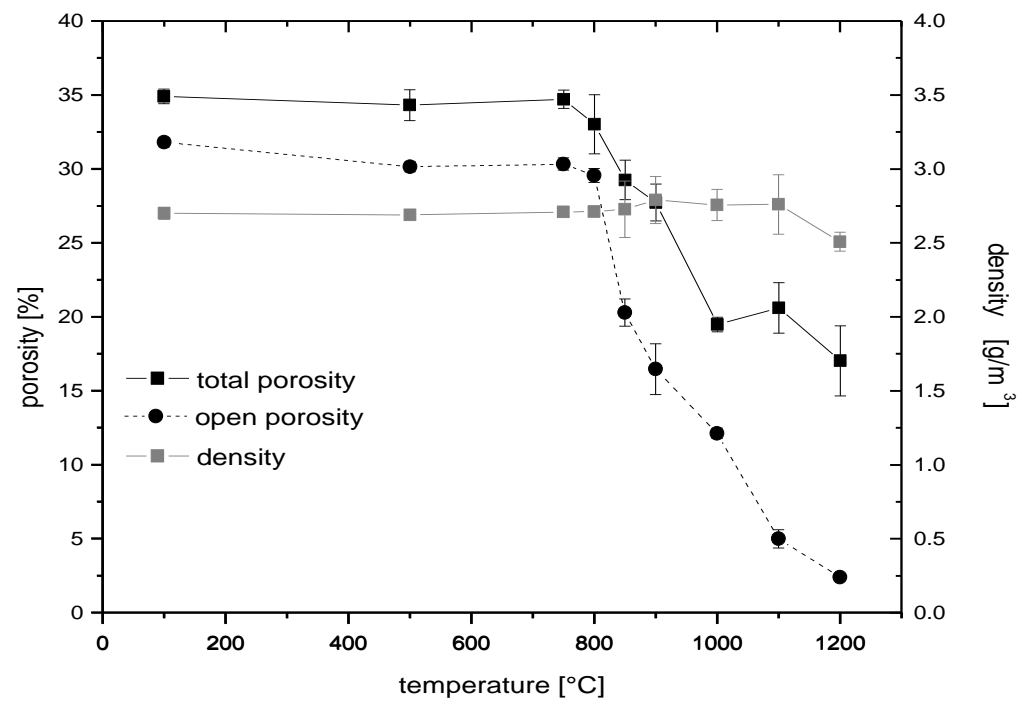

Figure 7: Porosity changes after exposure to different temperature for GP-medium. Very similar results were obtained for the other geopolymer mortar samples tested. Data presented is the average and standard deviation obtained from 5 measurements. 


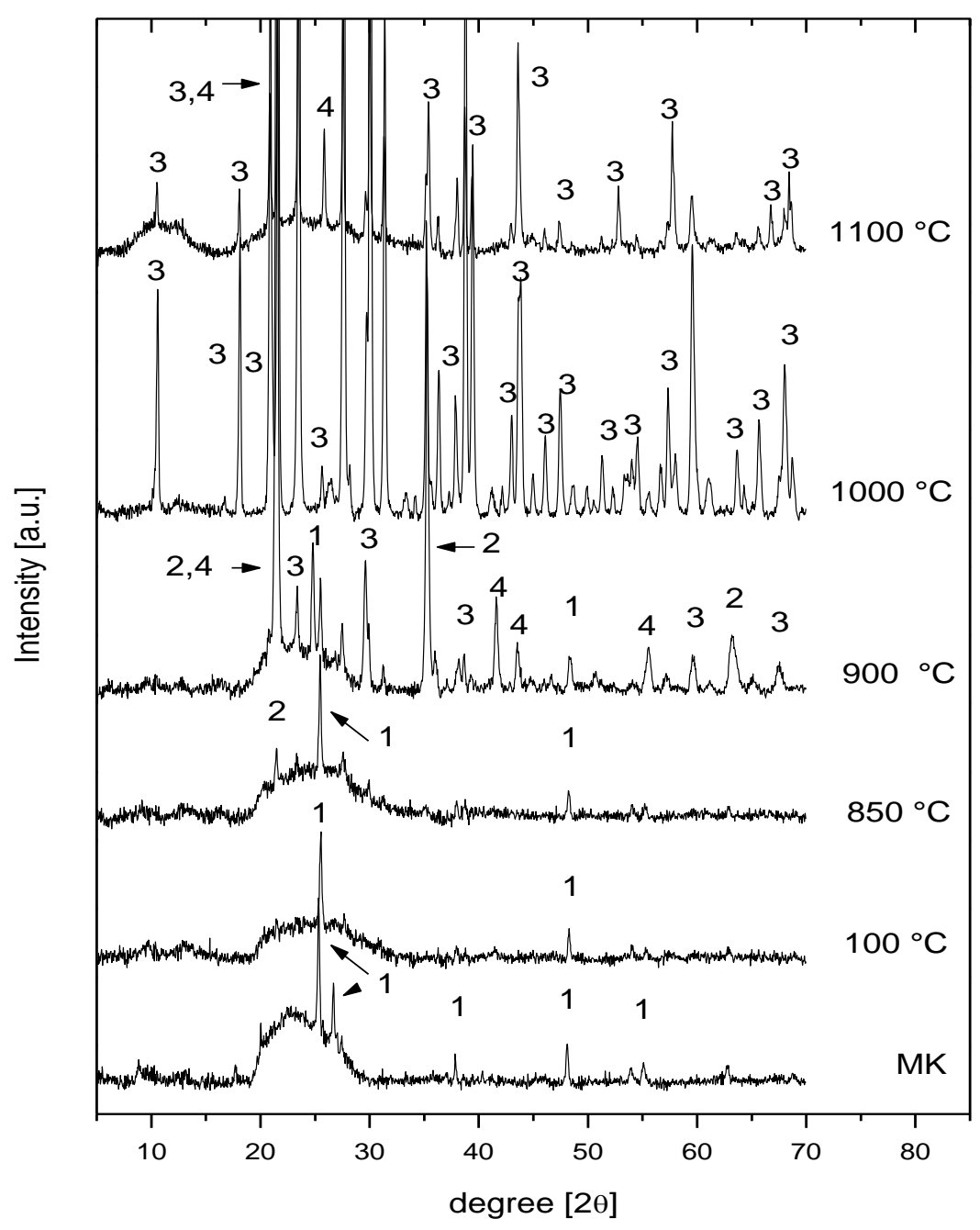

Figure 8: Change of crystalline phases after heating of pure geopolymer (pure GP) samples to different temperatures. Key: $1=$ quartz $\left[\mathrm{SiO}_{2}\right], 2=$ sodium aluminium silicate $\left[\mathrm{NaAlSi}_{2} \mathrm{O}_{6}\right]$, $3=$ nepheline $\left[\mathrm{NaAlSiO}_{4}\right], 4=$ carnegieite $\left[\mathrm{NaAlSiO}_{4}\right]$. 
a) $850{ }^{\circ} \mathrm{C}$
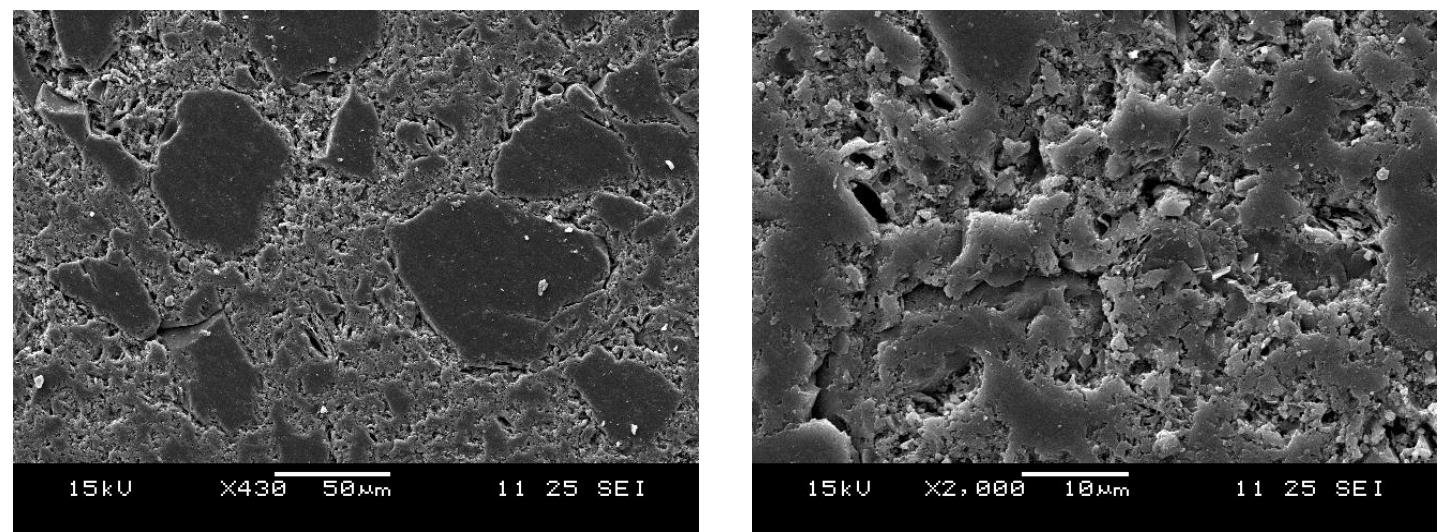

b) $900{ }^{\circ} \mathrm{C}$
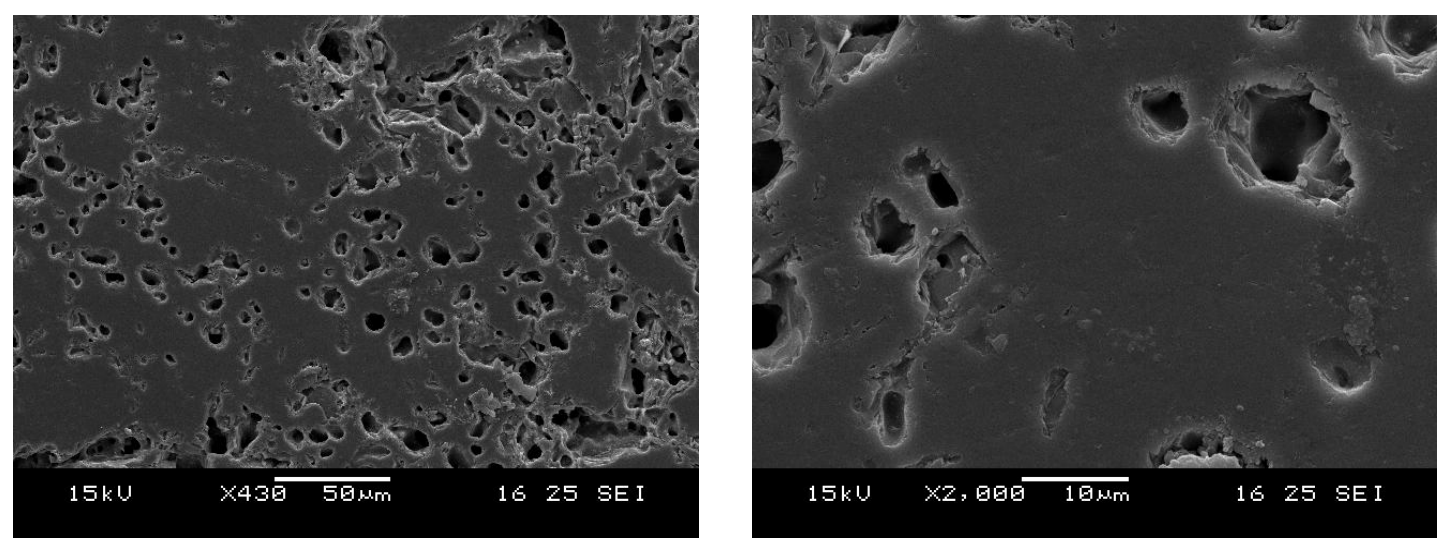

c) $1200{ }^{\circ} \mathrm{C}$
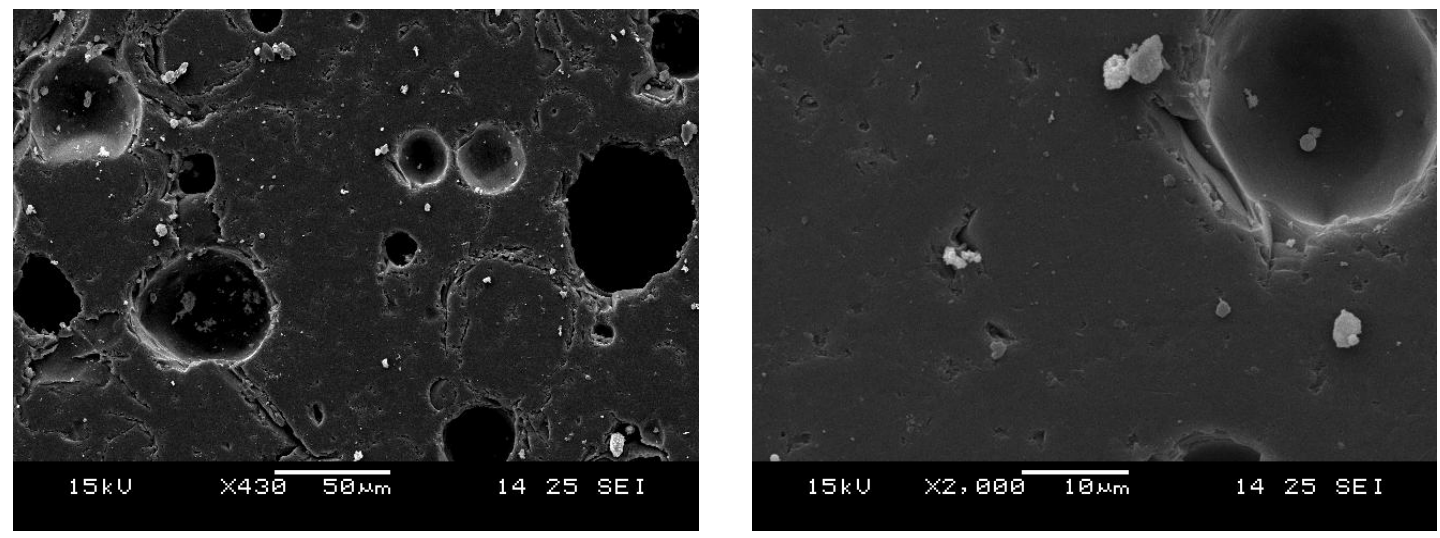

Figure 9: Backscattered electron micrographs of GP-medium after heating to a) $850^{\circ} \mathrm{C}, \mathrm{b}$ ) $900^{\circ} \mathrm{C}$ and c) $1200^{\circ} \mathrm{C}$ 


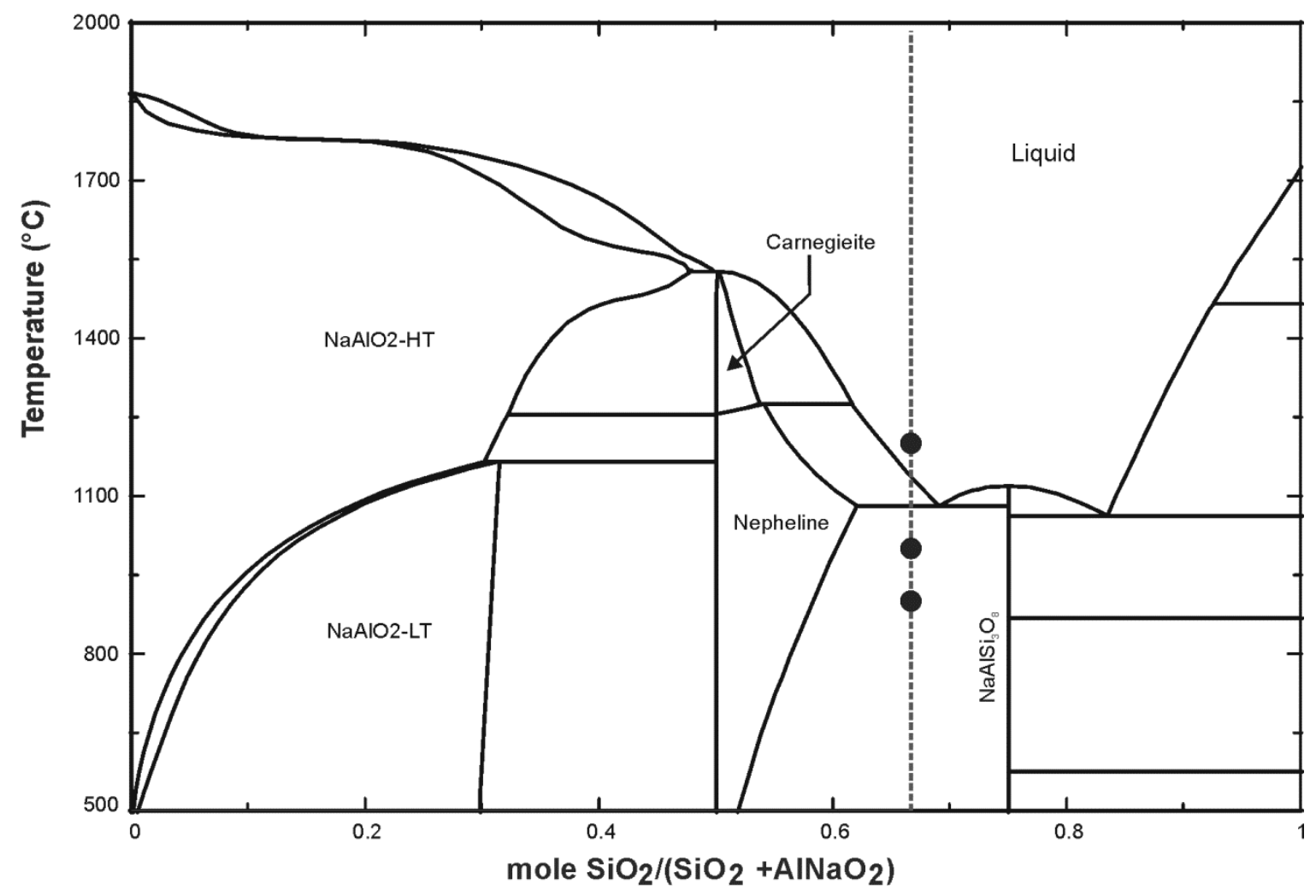

Figure 10: Phase diagram of $\mathrm{NaAlO}_{2}-\mathrm{SiO}_{2}$ modeled using FactSage 6.3, the line represents the pure geopoymer mixture [38]. 
Table 1: Physical properties of geopolymer (pure GP) and geopolymer mortar samples containing $50 \mathrm{wt} \%$ of course, medium or fine sand after curing for 75 days prior to testing.

\begin{tabular}{|c|c|c|c|c|c|c|c|c|}
\hline & \multicolumn{2}{|c|}{ Pure GP } & \multicolumn{2}{|c|}{ GP-coarse } & \multicolumn{2}{|c|}{ GP-medium } & \multicolumn{2}{|c|}{ GP-fine } \\
\hline & average & $\mathrm{SD}$ & average & $\mathrm{SD}$ & average & SD & average & $\mathrm{SD}$ \\
\hline Compressive strength [MPa] & 32.7 & 4.1 & 44.4 & 2.0 & 50.8 & 5.7 & 58.4 & 6.1 \\
\hline Flexural strength $[\mathrm{MPa}]$ & 7.3 & 0.7 & 13.3 & 1.5 & 13.8 & 0.8 & 13.6 & 1.3 \\
\hline Theoretical density $\left[\mathrm{g} / \mathrm{cm}^{3}\right]$ & 2.35 & 0.05 & 2.70 & 0.20 & 2.69 & 0.09 & 2.72 & 0.15 \\
\hline Total porosity [\%] & 59.1 & 0.5 & 31.9 & 0.6 & 34.7 & 0.6 & 34.8 & 0.5 \\
\hline Open porosity [\%] & 59.1 & 0.3 & 31.9 & 0.2 & 31.7 & 0.5 & 31.7 & 0.2 \\
\hline
\end{tabular}

SD: standard deviation 